\title{
Dark Tetrad and psychological distress among male violent offenders and male community adults
}

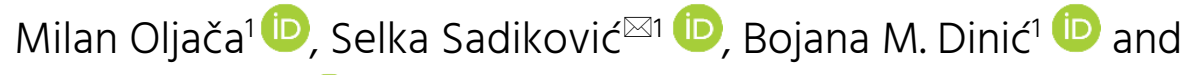
Valentina Baić ${ }^{2}$ iD

${ }^{1}$ Faculty of Philosophy, University of Novi Sad, Serbia

${ }^{2}$ University of Criminal Investigation and Police Studies in Belgrade, Serbia

\section{ABSTRACT}

The first aim of this study was to explore differences between male violent offenders and male community adults in Dark Tetrad traits and psychological distress. The second aim was to investigate moderation effects of dark traits in the prediction of psychological distress based on the membership of violent offenders or community adults. The sample included 142 male violent offenders $(M=40.73, S D=11.43)$ convicted of murder, severe murder, or rape, and 573 men from the community population in Serbia without a history of criminal convictions $(M=41.71, S D=15.11)$. Serbian adaptations of the Short Dark Triad (SD3), Comprehensive Assessment of Sadistic Tendencies (CAST), and Clinical Outcomes in Routine Evaluation - Outcome Measure (CORE-OM) were used. Results showed that violent offenders had higher scores on psychopathy and problems in social and general functioning, while community adults had higher scores on narcissism. Furthermore, moderation analyses showed that physical sadism was significantly correlated with risk behaviors in the community adults, but not in violent offenders.

Keywords: Dark Tetrad, psychological distress, violent offenders, prisoners, inmates 
UDC: 159.923.072:316.624

DOI: 10.19090/pp.2021.4. 509-537

Received: 20.09.2021.

Revised: 14.11.2021.

Accepted: 30.11.2021.
Copyright $\odot 2021$ The Author(s).

This is an open access article distributed under the terms of the Creative Commons Attribution License, which permits unrestricted use, distribution, and reproduction in any medium, provided the original author and source are credited.

$\bowtie$ Corresponding author email: selka.sadikovic@ff.uns.ac.rs 


\section{Introduction}

\section{Dark Tetrad}

The Dark Triad represents a constellation of three related socially aversive traits: Machiavellianism, narcissism, and psychopathy (Paulhus \& Williams, 2002). Seven years after this concept was introduced, sadism was included, forming the Dark Tetrad together with the previously mentioned traits (Chabrol et al., 2009). Based on Paulhus's (2014) review, the shared characteristic of Dark Teterad traits is callousness, and empirical studies showed that the central features of Dark Tetrad traits are lack of affective empathy (or callousness) and manipulativeness (e.g., Dinić, Wertag et al., 2020). Besides this common core, each dark trait has other unique characteristics or characteristics expressed in different intensities. Machiavellianism represents the tendency to exploit others for the purpose of realizing one's own goals and it is reflected in manipulativeness and insincerity accompanied by a cynical worldview (Jones \& Paulhus, 2009). Within Dark Triad and Dark Tetrad, a grandiose aspect of narcissism was mainly explored compared to other aspects. Thus, narcissism is characterized by a highly pronounced and unrealistic positive self-image and the experience of superiority and entitlement (Campbell \& Foster, 2007). Psychopathy is characterized by a reduced sense of guilt, a lack of empathy, disinhibition, and frequent manifestations of antisocial behavior (Hare \& Neumann, 2008). Finally, sadism is defined as the tendency to exhibit cruel and aggressive behavior towards others with the aim of achieving enjoyment or manifesting dominance (O'Meara et al., 2011).

The Dark Triad traits are regarded as risk factors for interpersonal problems, antisocial, and criminal behaviors in various domains, like intimate relationships and workplace (see Furnham et al., 2013). Meta-analysis has shown that among the Dark Triad traits, psychopathy is the most relevant when it comes to interpersonal violence, delinquency, sex-related issues, and antisocial tendencies (Muris et al., 2017). Since interest in sadism in research 
on dark traits emerged only a few years ago (Dinić \& Jevremov, 2019), many previous studies that investigated relationships between dark traits and antisocial behaviors did not include sadism. In the rare studies in which sadism was included, it was shown that both psychopathy and sadism predict antisocial behaviors in students (Chabrol et al., 2017) as well as vandalism (Pfattheicher et al., 2019).

\section{Dark Tetrad among violent offenders}

In a population in which violence is more prominent, such as prisoners convicted of crimes related to violent offenses, higher intensity of the dark traits could be expected. This seems to be likely for psychopathy since it is most related to various interpersonal problems and antisocial behaviors among Dark Triad traits (Muris et al., 2017) as well as to criminal recidivism (i.e., number of arrests, see Kavish et al., 2018). Indeed, violent offenders tend to show higher scores on psychopathy compared to perpetrators of non-violent transgressions (e.g., McCuish et al., 2015) or fraud offenders (Liu et al., 2017). Additionally, adults with high levels of psychopathy have higher odds of committing violent crimes (Dhingra et al., 2015; Klingzell et al., 2015), while young offenders with a high level of psychopathy have higher odds of manifesting violent behavior in correctional settings (Shaffer et al., 2015). Furthermore, both psychopathy and Machiavellianism were higher among delinquents compared to non-delinquents, while there were no differences in narcissism (Alsheikh Ali, 2020). In addition, Rogier et al. (2019) showed that violent offenders were not different in grandiose pathological narcissism compared to the community sample, but that they had higher vulnerable narcissism. When offenders convicted to different offenses were explored, Pettersen et al. (2019) showed that sexual offenders against children had lower scores on narcissism compared to the offenders who haven't committed sexual offenses toward children.

In rare studies that included sadism, it was shown that juvenile offenders (those who reported moderate and severe antisocial behaviors, mostly included physical violence) had higher psychopathy, Machiavellianism, 
and sadism compared to non-offenders, but the level of narcissism was the same in both groups (Chabrol et al., 2009). Furthermore, violent offenders showed higher spitefulness, a tendency close to sadism, compared to the community sample (Rogier et al., 2019).

We should note that in a more diverse prison population, comprised of prisoners convicted of various types of offenses not limited to violent offenses, some studies showed different results. For example, Boduszek et al. (2021) showed that prisoners had higher deficits in cognitive responsiveness, as one of the psychopathy facets, compared to university students and community adults, while there are no significant differences in affective responsiveness. In the same study, prisoners showed lower scores on interpersonal manipulation and egocentricity compared to university students and/or community sample. Furthermore, Thiry (2012) showed that narcissistic personality disorder, as the disorder that has grandiosity and entitlement as its core like subclinical narcissism within Dark Triad/Tetrad, is less common in a prisoner sample, which in line with the study by Hepper et al. (2014) showed that there are no differences in narcissistic personality disorder among prisoners and community samples. However, Hepper et al. (2014) pointed out that prisoners had higher subclinical narcissism compared to community sample without a history of criminal convictions. In research by Wiench (2019) in which a broader constellation of dark traits was used, prisoners showed higher scores only on moral disengagement compared to non-prisoners, and not in the rest of the dark traits. Taken together, it seems that higher psychopathy, Machiavellianism and sadism could be expected in violent offenders, while for narcissism previous results are not consistent. Furthermore, higher mentioned dark traits seem to be characteristic of violent offenders, compared to diverse samples of offenders.

\section{Dark Tetrad and mental health}

Emotional deficits and social malevolence of dark traits come with mental health costs. Jonason et al. (2015) showed that among Dark Triad traits, 
Machiavellianism and psychopathy positively predicted depression and anxiety and negative psychological, emotional, and social well-being, while narcissism showed smaller positive contribution to the prediction of anxiety, but also positive to the prediction of mentioned aspects of well-being. These results indicate that narcissism could provide a buffer from negative health outcomes. Other studies also confirmed this effect. For example, although all dark traits are related to anxiety, only narcissism was not related to depressive symptoms (Gómez-Leal et al., 2019) or showed negative relations with both depression and anxiety (Lyons et al., 2019). Narcissism is also positively connected with some indicators of positive mental health, e.g., with happiness (Egan et al., 2014). A meta-analysis showed that psychopathy, followed by Machiavellianism, was related to poor well-being, while narcissism was unrelated to it (Murris et al., 2017). Results from newly published research (Joshanloo, 2021; Van Groningen et al., 2021) replicated the negative relationship between well-being and psychopathy and Machiavellianism and showed that grandiose narcissism was positively related to well-being.

Studies that included sadism showed that sadism and psychopathy are more related to psychological distress domains, compared to Machiavellianism, while narcissism showed negative correlations with poor well-being, but positive with risk behaviors (Dinić, Sadiković et al., 2019). Moreover, the inclusion of sadism into the constellation of the dark traits resulted in forming the high Dark Tetrad-sadism profile, which showed more risk behaviors towards others and oneself, compared to the high Dark Tetrad profile (Dinić, Sadiković et al., 2019). Sadism explained unique variance in suicidality over and above depression, substance abuse, borderline traits, and attachment (Chabrol et al., 2011). Although sadism was positively related to psychological symptoms and poor functioning (Dinić, Sadiković et al., 2019) as well as with negative affect (Womick et al., 2019) it showed non-significant relations with well-being (Dinić, Sadiković et al., 2019; Womick et al., 2019). Although there are not many studies in which sadism is connected with mental health outcomes, we could conclude, based on mentioned results, 
that it can have an important role in explaining some aspects of poor mental health.

\section{The present study}

The first aim of this study was to explore differences between male violent offenders and male community adults in Dark Tetrad traits as well as in psychological distress. We were focused on violent offenders, since previous studies showed higher some of the dark traits, i.e., psychopathy among violent offenders compared to non-violent offenders (e.g., McCuish et al., 2015; Liu et al., 2017). Based on previous research (e.g., Chabrol et al., 2009; Rogier et al., 2019) we expected to find higher scores in psychopathy, Machiavellianism, and sadism among violent offenders, but not in narcissism.

The increased risk of poor mental health for the prisoners is well documented in previous research (Edgemon \& Clay-Warner, 2019; Fazel \& Seewald, 2012; Porter \& DeMarco, 2019; Yi et al., 2017). Imprisonment is related to a greater risk of developing depression and other mood disorders and lower life satisfaction compared to the general population (Yi et al., 2017). Additionally, one in seven prisoners suffers from major depression or psychosis (Fazel \& Seewald, 2012). Characteristics of prison environments, like overcrowding, as well as the length of time in prison, are related to depressive symptomology and hostility (Edgemon \& Clay-Warner, 2019; Porter \& DeMarco, 2019). Thus, we expected to find higher various domains of psychological distress among violent offenders compared to community adults.

The second aim was to explore the moderation role of Dark Tetrad traits in the prediction of psychological distress based on membership of violent offenders or community adults. Within this analysis, firstly we explore predictive effects of both subsample's membership and dark traits on various psychological distress domains. We already noted that we expect higher psychological distress among violent offenders compared to community adults. However, in the case of effects of dark traits, previous studies were 
focused only on one domain of psychological distress, for example, on negative affect (e.g., Gómez-Leal et al., 2019; Lyons et al., 2019). In this study we expanded the range of indicators, including affective, cognitive, somatic, and behavioral aspects of psychological distress. Based on previous studies (e.g., Jonason et al., 2015; Dinić, Sadiković et al., 2019; Murris et al., 2017) we expect that among Dark Tetrad traits, psychopathy and sadism show the most prominent relationships with various distress domains, especially those related to problems in interpersonal functioning given that the core features of dark traits referring to interpersonal difficulties (e.g., Dinić, Wertag et al., 2020). However, in the case of narcissism we could expect non-significant or negative relationships with distress (e.g., Jonason et al., 2015; Murris et al., 2017).

Regarding the moderation role of dark traits, there are two conflicting approaches. Since dark traits should be more expressed in violent offenders (e.g., McCuish et al., 2015) and they should be related to poor mental health (e.g., Dinić, Sadiković et al., 2019; Murris et al., 2017), we could expect that violent offenders with higher dark traits showed higher distress, meaning that dark traits among violent offenders could increase distress. However, some studies indicated the adaptive role of dark traits in specific contexts. For example, Machiavellians successfully navigate competitive work environments by undermining their coworker (Castille et al., 2017). There are some assumptions that personality traits also can have an adaptive role in correctional settings. Although typical results from the number of previous research (for details see Eriksson et al., 2017) suggested that prisoners have lower scores on Agreeableness and Conscientiousness and higher scores on Neuroticism, in comparison to the general population, those results were challenged in several previous research (Eriksson et al., 2017; Thiry, 2012; Trninić et al., 2008) that showed that prisoners have higher scores on Agreeableness and/or Conscientiousness. Those differences were interpreted as the result of personality changes or short-term adjustments in response to the demands of the prison environment (Eriksson et al., 2017). Thus, in the prison setting, we could assume that dark personality traits could be related to adaptive 
strategies, i.e., that they provide a "buffer" from negative outcomes. Therefore, based on this approach, although we expect that distress is higher among violent offenders if the dark traits are higher among them, we can assume that they could reduce distress.

\section{Method}

\section{Participants and procedure}

The study included two subsamples from Serbia. The first subsample consisted of 142 male violent offenders, aged 23 to $78(M=40.73, S D=11.43)$, who were serving their prison sentence (ranged from 2 to 40 years, $M=19.10$; $S D=11.85$ ) in four penitentiary correctional institutions in Serbia (in Sremska Mitrovica, Belgrade, Požarevac, and Niš), for criminal offenses definite in the Criminal Code of the Republic of Serbia (Službeni glasnik, 2005) murder (28.9\%), severe murder (48.6\%) and rape (22.5\%). Most of them finished high school $(54.9 \%)$ or elementary school $(22.9 \%)$. The data were collected during the second half of 2019, by a trained psychologist in the correctional institutions. The examination was conducted voluntarily, in small groups of the participants, in the presence of a psychologist who works in the correctional institution. Prison officers or researchers were not present at the examination due to prison policy when research is conducted in prisoners. Thus, the sample was convenient.

The second subsample included 573 males from the general population (non-offenders) from Serbia, aged between 20 and 84 ( $M=41.71$, $S D=15.11)$. Most of them finished high school (50.6\%) and elementary school (20.4\%). Data collection was conducted in the first half of 2020. A convenient sampling method was used. The data were collected by trained undergraduate psychology students for course credits. In order to get a heterogeneous sample, each student had to collect data from a specific number of participants, based on the given educational and age quotas in line with the characteristics of the prison subsample. 
All participants signed the informed consent form including the anonymity agreement with regard to the confidentiality of the data. Also, all participants responded to questionnaires in pen-and-paper format. Participation in the research was voluntary.

There were no significant differences in age $(t(712)=0.67, p=.50)$, but there were in education (Mann-Whithey $U=35288.50, p=.02$ ) between the subsamples, with males from the general population having higher education levels.

\section{Measures}

Short Dark Triad (SD3)

Short Dark Triad (SD3; Jones \& Paulhus, 2014, for Serbian adaptation see Dinić et al., 2018) comprises 27 items measuring the Dark Triad traits: Machiavellianism, narcissism, and psychopathy (9 items per trait).

Comprehensive Assessment of Sadistic Tendencies (CAST)

Comprehensive Assessment of Sadistic Tendencies (CAST; Buckels \& Paulhus, 2014, for Serbian adaptation see Pfattheicher et al., 2021) measures direct verbal sadism (6 items) referring to being mean to someone, enjoying making jokes at the expense of others, purposely tricked someone and laughed when they looked foolish, etc.; physical sadism (5 items) referring to enjoying in physically hurting pole, tormenting people, dominated others using fear, etc.; and vicarious sadism (7 items) referring to enjoyment in various violent video content (video games, movies, YouTube clips, cage fighting, car accidents...) as well as in playing the villain in games and torturing other characters.

Clinical Outcomes in Routine Evaluation - Outcome Measure (CORE-OM)

Clinical Outcomes in Routine Evaluation - Outcome Measure (COREOM; Evans et al., 2000, for Serbian adaptation see Dinić, Sadiković et al., 2020) is a 22-item measure of the experience of various manifestations of psychological distress over the past six months and comprises four scales: (poor) subjective well-being ( 4 items) which refers to sense of life quality and 
emotional health (feeling O.K. about myself, feeling like crying, feeling overwhelmed by problems, optimism); problems/symptoms (12 items) which refers to psychological health issues such as anxiety and depression symptoms, reactions to trauma, and physical complaints; (poor) functioning (12 items), referring to problems in interpersonal, social, and general functioning in daily life (e.g., feeling of loneliness, lack of social support, inability to cope with problems, lack of warmth and affection for someone, been irritable with others, failure to achieve wanted things, etc.); and risk, referring to risk-to-self ( 4 items) which measure harm to self and suicidal ideations, and risk-to-others (2 items) which measure violent behavior and threats towards others. In line with previous validations of CORE-OM, the two kinds of risk were separated (e.g., Lyne et al., 2006).

All instruments have a 5-point Likert type scale (from $1=$ strongly disagree to 5 = strongly agree). Descriptives and Cronbah's $\alpha$ are presented in Table 1.

\section{Data analysis}

First, descriptive statistics were calculated. Since some variables showed normality violation, they were normalized by rankit normalization. Second, differences in Dark Tetrad traits and distress domains between violent offenders and participants from the general population were tested. Since these two subsamples were different in education, education was added as a covariate in the univariate general linear model. Effect size was calculated as $\eta_{p}{ }^{2}$, which should be up to .06 for small, from .07 to .14 for medium, and above .14 for large effects (Cohen, 1988). Additionally, the same analysis was used to test differences between the offenders regarding the type of criminal offenses. This analysis was included to check the homogeneity of offenders subsample regarding the used variables, or more precisely, to check whether offenders convicted of all three criminal offenses could be treated as one group in further analyses. Third, correlations between all variables were calculated on the total sample. In order to avoid Type I error, 
we interpreted only correlations with $p<.001$. Finally, hierarchical regression analysis was used to explore moderation effects of dark traits in the prediction of psychological distress based on the membership of the violent offenders' community adults. In the first step education was entered as control, in the second step membership of the subsamples was entered, in the third step Dark Tetrad traits were entered, and in the last step interactions between the subsample membership and Dark Tetrad traits were entered. All continuous variables were standardized before the moderation analyses. All statistical analyses were conducted in the SPSS for Windows v.26 (IBM Corp., 2019).

\section{Results}

Descriptives and differences between male violent offenders and male community adults

Preliminary analysis showed that physical sadism, risk-to-self, and riskto-others had skewness and/or kurtosis over recommended for normal distribution ( \pm 2 , see George \& Mallery, 2010), thus scores for these variables were normalized by rankit normalization. The rest of the variables had acceptable values of skewness and kurtosis (in a range from -0.18 to 1.88, SE for skewness was 0.09 and for kurtosis was 0.18). The results of differences between the subsamples showed that violent offenders had higher scores on psychopathy and poor functioning, while community adults had higher scores on narcissism (Table 1). However, all differences were small in terms of effect size. Additionally, among violent offenders, there were no significant differences in all variables regarding the type of criminal offenses - murder, severe murder, and rape $(F(2,7136)$ ranged from 0.20 to 2.76 , all $p>.05)$. Thus, we could consider this subsample of violent offenders as homogeneous regarding the used variables. 


\section{Table 1}

Descriptives and differences between the male violent offenders and male community adults

\begin{tabular}{lccccc}
\hline & $\begin{array}{c}\text { Community/Offend } \\
\text { ers }\end{array}$ & $\begin{array}{c}\text { Community } \\
(n=573)\end{array}$ & $\begin{array}{c}\text { Offenders } \\
(n=141)\end{array}$ & \multicolumn{2}{c}{$\begin{array}{c}\text { Subsamples } \\
\text { differences }\end{array}$} \\
\hline Dark Tetrad traits & $\alpha$ & $M(S D)$ & $M(S D)$ & $f(1,710)$ & $\eta_{\mathrm{p}}{ }^{2}$ \\
\cline { 2 - 6 } Machiavellianism & $.76 / .72$ & $27.62(6.14)$ & $27.63(6.27)$ & 0.01 & .000 \\
Narcissism & $.63 / .55$ & $25.13(5.30)$ & $23.35(5.31)$ & $11.06^{\star * \star}$ & .015 \\
Psychopathy & $.76 / .82$ & $18.81(6.16)$ & $20.53(7.20)$ & $6.81^{\star *}$ & .010 \\
Physical sadism & $.78 / .87$ & $6.20(2.32)$ & $6.38(2.87)$ & 0.00 & .000 \\
Verbal sadism & $.70 / .67$ & $11.56(4.23)$ & $11.67(4.15)$ & 0.14 & .000 \\
Vicarious sadism & $.73 / .76$ & $13.87(4.93)$ & $14.49(5.35)$ & 1.48 & .002 \\
\hline Psychological & & & & & \\
distress & & & & & \\
Poor well-being & $.61 / .54$ & $8.88(2.79)$ & $9.32(3.02)$ & 1.37 & .002 \\
Problems & $.87 / .90$ & $28.13(8.09)$ & $28.85(9.21)$ & 0.21 & .000 \\
Poor functioning & $.80 / .77$ & $25.48(6.56)$ & $27.62(7.28)$ & $7.96^{\star *}$ & .011 \\
Risk-to-self & $.80 / .70$ & $5.03(2.20)$ & $5.45(2.49)$ & 0.28 & .000 \\
Risk-to-others & $.67 / .74$ & $2.84(1.42)$ & $2.92(1.42)$ & 0.18 & .000 \\
\hline
\end{tabular}

Notes: Education level was added as a covariate in the univariate general linear model analysis for testing the differences between two samples. ${ }^{* \star} p<.001 ;{ }^{* *} p<.01$.

\section{Correlations between Dark Tetrad traits and psychological distress}

Correlations between the Dark Tetrad traits and psychological distress domains in the total sample were all positive, except for relationships between narcissism on the one side and poor well-being and poor functioning on the other side (Table 2). However, narcissism seems generally unrelated to psychological distress and showed a significant and positive correlation at $p<.001$ only with risk-to-others. Psychopathy and physical sadism showed the highest correlations with distress domains, especially with risk-to-others.

Correlations among Dark Tetrad traits were in range from .27 (between narcissism and physical sadism) to .55 (between psychopathy and 
physical sadism as well as between physical and vicarious sadism). Furthermore, correlations between the psychological distress domains were in range from .19 (between poor well-being and risk-to-others) to .75 (between poor well-being and poor functioning).

\section{Table 2}

Correlations between the Dark Tetrad traits and psychological distress domains ( $N=$ 714)

\begin{tabular}{|c|c|c|c|c|c|c|}
\hline & Machiavellianism & Narcissism & Psychopathy & $\begin{array}{l}\text { Physical } \\
\text { sadism }\end{array}$ & $\begin{array}{l}\text { Verbal } \\
\text { sadism }\end{array}$ & $\begin{array}{c}\text { Vicarious } \\
\text { sadism }\end{array}$ \\
\hline $\begin{array}{l}\text { Poor well- } \\
\text { being }\end{array}$ & .02 & $-.08^{\star}$ & $.08^{*}$ & $.12^{\star \star \star}$ & .04 & .05 \\
\hline Problems & $.17^{\star \star \star}$ & .02 & $.19^{\star \star \star}$ & $.16^{\star \star \star}$ & $.12^{\star \star}$ & $.10^{\star *}$ \\
\hline $\begin{array}{l}\text { Poor } \\
\text { functioning }\end{array}$ & $.09^{\star}$ & $-.09^{*}$ & $.25^{\star \star \star}$ & $.22^{\star \star \star}$ & $.12^{\star \star \star}$ & $.12^{\star \star \star}$ \\
\hline Risk-to-self & $.11^{\star \star}$ & .02 & $.24^{\star \star \star}$ & $.24^{\star \star \star}$ & $.14^{\star \star \star}$ & $.12^{* *}$ \\
\hline $\begin{array}{l}\text { Risk-to- } \\
\text { others }\end{array}$ & $.27^{\star \star \star}$ & $.26^{\star \star \star}$ & $.53^{\star \star \star}$ & $.41^{\star \star \star}$ & $.37^{\star \star \star}$ & $.39^{\star \star *}$ \\
\hline
\end{tabular}

Notes: ${ }^{* \star *} p<.001,{ }^{* \star} p<.01,{ }^{*} p<.05$.

\section{Moderation analyses}

In the moderation analyses, education level was entered in the first step, subsample membership in the second step, dark traits in the third step, and interaction between the membership and dark traits in the last step in hierarchical regression analyses. Results showed that subsample membership was not significant predictor of psychological distress domains (Table 3). Dark Tetrad traits contribute to the prediction of distress domains. While narcissism was negatively related to poor well-being, poor functioning, and risk-to-self, other dark traits were positively related; especially psychopathy, with poor functioning and both risk aspects. The only significant interactions were found between subsample membership and physical sadism in prediction of both risk-to-self and risk-to-others. Although $\Delta R^{2}$ was not significant for the last step in the prediction of risk-to-self, beta contribution 
was significant, while both $\Delta R^{2}$ and beta contribution were significant in the prediction of risk-to-others. In both cases, physical sadism was significantly correlated with both risks in community adults (risk-to-self: $r=.30, p<.001$; risk-to-others: $r=.48, p<.001)$, while these correlations were not significant in violent offenders (risk-to-self: $r=.04, p=.68$; risk-to-others: $r=.16, p=.065$ ). More detailed results from all moderation analyses are shown in the Table $A$ in Supplement. 


\section{Table 3}

Moderation effects of Dark Tetrad traits in the prediction of psychological distress domains based on the subsample membership (male violent offenders or male community adults)

\begin{tabular}{|c|c|c|c|c|c|}
\hline Predictors & $\begin{array}{c}\text { Poor well- } \\
\text { being }\end{array}$ & Problems & $\begin{array}{c}\text { Poor } \\
\text { functioning }\end{array}$ & $\begin{array}{l}\text { Risk-to- } \\
\text { self }\end{array}$ & $\begin{array}{l}\text { Risk-to- } \\
\text { others }\end{array}$ \\
\hline Education & $-.18^{\star \star \star}$ & $-.12^{\star \star}$ & $-.14^{\star \star}$ & -.09 & -.06 \\
\hline$R^{2}$ & $.03^{* * *}$ & $.02^{\star *}$ & $.03^{* * *}$ & $.01^{*}$ & .00 \\
\hline $\begin{array}{l}\text { Subsample } \\
\text { membership }\end{array}$ & -.02 & -.02 & -.02 & -.01 & -.01 \\
\hline$\Delta R^{2}$ & .00 & .00 & .00 & .00 & .00 \\
\hline Machiavellianism & .00 & $.12^{\star \star}$ & .02 & .01 & -.01 \\
\hline Narcissism & $-.11^{*}$ & -.08 & $-.21^{\star \star \star}$ & $-.10^{* *}$ & .03 \\
\hline Psychopathy & .06 & $.13^{*}$ & $.25^{\star \star \star}$ & $.21^{\star \star \star}$ & $.40^{\star \star \star}$ \\
\hline Physical sadism & $.13^{\star}$ & .09 & $.14^{\star \star}$ & $.19^{\star \star \star}$ & $.11^{\star}$ \\
\hline Verbal sadism & .00 & .02 & .00 & .00 & .05 \\
\hline Vicarious sadism & -.02 & -.04 & -.03 & -.06 & $.09^{*}$ \\
\hline$\Delta R^{2}$ & $.02 * \star$ & $.05^{\star \star \star}$ & $.10^{\star \star \star}$ & $.09^{\star \star \star}$ & $.32^{\star \star \star}$ \\
\hline $\begin{array}{l}\text { Machiavellianism x } \\
\text { subsample }\end{array}$ & -.01 & -.05 & -.03 & -.01 & .06 \\
\hline $\begin{array}{l}\text { Narcissism x } \\
\text { subsample }\end{array}$ & .02 & -.01 & .03 & .01 & -.03 \\
\hline $\begin{array}{l}\text { Psychopathy x } \\
\text { subsample }\end{array}$ & .03 & .02 & -.01 & .02 & .00 \\
\hline $\begin{array}{l}\text { Physical sadism x } \\
\text { subsample }\end{array}$ & -.07 & -.05 & -.03 & $-.11^{\star}$ & $-.17^{\star \star \star}$ \\
\hline $\begin{array}{l}\text { Verbal sadism x } \\
\text { subsample }\end{array}$ & .06 & .07 & .05 & -.01 & .06 \\
\hline $\begin{array}{l}\text { Vicarious sadism x } \\
\text { subsample }\end{array}$ & -.05 & -.06 & -.08 & .01 & .00 \\
\hline$\Delta R^{2}$ & .00 & .01 & .00 & .01 & $.2^{\star \star \star}$ \\
\hline Total $R^{2}$ & $.05^{\star \star \star}$ & $.06^{\star \star \star}$ & $.12^{\star \star \star}$ & $.09^{\star \star \star}$ & $.35^{\star \star \star}$ \\
\hline
\end{tabular}

Notes: Subsample membership was coded as $0=$ male community adults, $1=$ male violent offenders. Tolerance indices for all analyses were $>.20$, which indicated that there was no problem with multicollinearity (Hair et al., 1995). ${ }^{\star \star \star} p<.001,{ }^{\star \star} p<.01,{ }^{\star} p$ $<.05$. 


\section{Discussion}

The first aim of this study was to explore differences between male violent offenders and male community adults in Dark Tetrad traits and psychological distress domains. Results showed that violent offenders had higher scores on psychopathy and poor functioning but lower on narcissism, compared to community adults. Higher scores in psychopathy among violent offenders were expected and in line with previous studies (e.g., McCuish et al., 2015). Certain features of psychopathy, like impulsivity and lack of empathy, increase the likelihood of engaging in violent criminal activities and offenses (Dhingra et al., 2013). However, lower scores on narcissism among violent offenders were not expected. Although there was a research showing lower narcissism in specific violent offenders such as sexual offenders against children (Pettersen et al., 2019), most of the previous research (e.g., Alsheikh Ali, 2020; Rogier et al., 2019) showed non-significant differences between offenders and the general population. It could be possible that being in prison can have a decreasing effect on positive self-perception, which is an indicator of grandiose narcissism, but this finding needs further investigation. In addition, we could assume that specific types of crime, such as murder and rape, contribute to the negative self-image among offenders convicted for these crimes. Our results could be interpreted in light of Campbell and Foster (2007) notion that if one of the elements of the narcissism self-regulatory system is not working, this will lead to lower narcissistic esteem. From this standpoint, being in prison impede self-regulatory activities which contribute to the lower narcissistic esteem.

Furthermore, violent offenders showed poorer functioning compared to community adults. Previous research showed poor mental health among prisoners (e.g., Edgemon \& Clay-Warner, 2019; Porter \& DeMarco, 2019). However, our research showed that the main domain of mental health that contributed to the differences between the subsamples is poor social and general function and not poor well-being, symptoms or risk behaviors. In one review study (Saladino et al., 2021) it was stated that violent offenders are 
characterized by poor social and life skills and that many of them manage stress and anger solely through violent action or aggressive acting-out, not showing problem-solving and decision-making skills. Thus, the results of our study confirmed the presence of interpersonal deficits and problem-solving strategies among violent offenders as the most problematic aspects of their mental health.

The second aim was to explore moderation effects of dark traits in relationships between subsample membership and psychological distress. Results of hierarchical regression analyses when subsample membership was controlled, showed that psychopathy and physical sadism had positive effects on various domains of psychological distress, which is in line with previous studies (e.g., Chabrol et al., 2011; Dinić, Sadiković et al., 2020; Lyons et al., 2019). Since a broader set of indicators of mental health were used in our study, results indicated that deficits in social and problem-solving skills are the most linked to these dark traits, compared to poor well-being or symptoms. This is in line with the evaluation of dark traits as socially toxic traits (Paulhus \& Williams, 2002) with costs on interpersonal relationships. Although previous research documented significant relationships between sadism and risk-to-others (Dinić, Sadiković et al., 2020), our study further contributes to the better insight into relationships between types of sadism and distress domains. Thus, in our study only physical sadism was related to the risk-to-others and showed substantive correlations with other aspects of distress, compared to verbal or vicarious sadism. These results indicated that only direct, physical sadism seems important in relationship to mental health domains. Previous research found that only direct sadism showed incremental validity in the prediction of some outcomes, e.g., attitudes towards various groups, and not vicarious (Dinić et al., 2020).

In line with our expectations, narcissism showed a negative link with poor functioning, risk behaviors, and poor well-being when subsample membership was controlled. Previous studies indicated the potential protective role of narcissism due to self-aggrandizement and higher selfesteem (e.g., Joshanloo, 2021). Furthermore, narcissism is characterized as the 
most "social" trait which acts as a "buffer" for health costs due to the benefits of easily making social connections (Jonason et al., 2015).

Furthermore, the moderation effect of dark traits in relationships between subsample membership and psychological distress was found only for physical sadism. Thus, only among community adults the relationships between physical sadism and both risk aspects were significant in expected negative direction. The negative relationship was in line with previous research on the general population (Dinić, Sadiković et al., 2020). However, a non-significant relationship in violent offenders could have two main implications. First, we could assume that in the prison setting sadistic tendencies could be related to adaptive or surviving strategies, i.e., that they provide a "buffer" from negative outcomes. Second, it is possible that in prisoners some other factors of the environment can potentially suppress this relationship. For example, strict control of behavior and punishment for aggressive behavior, which are more prominent in the correctional setting. In both cases, future research is warranted.

There were several limitations to this study. First, all participants were men since we only had access to male prisons. Despite the higher importance of callous psychopathic traits in predicting chronic violent misconducts among female offenders, Thomson et al. (2016) concluded that there was a similarity between men and women in predicting violent behavior. However, since there are gender differences in dark traits (e.g., Dinić et al., 2018), future studies should include female violent offenders in order to further investigate the potential moderation role of dark traits. Second, only self-report measures were used, thus there is a possibility of socially desirable responses, especially when they measure socially undesirable constructs. However, research showed that those scoring higher on more antagonistic traits (such as Machiavellianism and psychopathy, but also aggression) are less concerned with social desirability, at least among the general population (e.g., Kowalski et al., 2018). Third, the alpha reliability is marginal for narcissism and poor wellbeing scales, which could affect the results. It is possible these low alphas are 
a product of the sample surveyed, given these alphas are typically established in community/undergraduate samples. Future research should include multidimensional measures of Dark Triad traits and both self-report and others-report measures in order to control potential response biases. Furthermore, considering the lack of research exploring the role of sadism in mental health, the findings regarding the role of sadism in mental health outcomes warrant replication. Finally, offenders convicted of other violent offenses could be included (e.g., robbery) and possible differences between a broader set of offenses types could be investigated. Besides membership of various violent offenses, criminal recidivism could be taken into account also, including not only recidivism related to violent crimes, but crimes in general.

Despite these limitations, the results of this study add to the better understanding of differences between violent offenders and non-offenders as well as to the better understanding of the role of Dark Tetrad traits in explanation of mental health among both violent offenders and nonoffenders. The result showed that violent offenders had higher psychopathy but lower narcissism compared to community adults. Furthermore, results indicate that among mental health indicators, loneliness, lack of social support and adequate coping strategies were the most important distinction between these subsamples. Results highlighted the important role of psychopathy and physical sadism in the prediction of poor mental health, while narcissism, as "the brightest" trait among dark traits (Rauthmann \& Kolar, 2012), showed negative relations with psychological distress. However, it seems that mentioned effect of physical sadism holds only among community adults, while among violent offenders physical sadism showed non-significant relationships with distress.

From the practical perspective, the results from this study imply two important aspects for further development of the prevention programs and training in correctional settings. First, treatment program for violent offenders should be focused on adoption of adequate social, conflict, and problemsolving strategies. Second, our results implicate that a better implementation 
of prevention programmes that includes these skills and strategies is needed. All together, empowerment of the psychological functioning in these aspects could be beneficial for both violent prisoners and society in general.

Acknowledgment

We are thankful to our colleague Bojan Branovački for his help in preliminary statistical analysis for this paper.

\section{Funding}

This research was partly supported by the Ministry of Education, Science, and Technological Development of the Republic of Serbia (\#179006).

\section{Conflict of Interest}

We have no conflicts of interest to disclose.

Data availability statement

Data used in this paper is available at: https://osf.io/dctre/.

\section{References}

Alsheikh Ali, A. S. (2020). Delinquency as predicted by dark triad factors and demographic variables. International Journal of Adolescence and Youth, 25(1), 661-675. http://doi.org/10.1080/02673843.2020.1711784

Boduszek, D., Debowska, A., Sherretts, N., Willmott, D., Boulton, M., Kielkiewicz, K., ... \& Hyland, P. (2021). Are prisoners more psychopathic than nonforensic populations? Profiling psychopathic traits among prisoners, community adults, university students, and adolescents. Deviant Behavior, 42(2), 232-244. https://doi.org/10.1080/01639625.2019.1665221

Buckels, E.E., \& Paulhus, D.L. (2014). Comprehensive assessment of sadistic tendencies (CAST). Unpublished instrument, Vancouver, Canada: University of British Columbia.

Campbell, W.K., \& Foster, J.D. (2007). The narcissistic self: Background, an extended agency model, and ongoing controversies. In C. Sedikides \& 
S.J. Spencer (Eds.), Frontiers of social psychology. The self (pp. 115-138).

New York, NY: Psychology Press.

Castille, C.M., Kuyumcu, D., \& Bennett, R.J. (2017). Prevailing to the peers'

detriment: Organizational constraints motivate Machiavellians to

undermine their peers. Personality and Individual Differences, 104, 29-

36. https://doi.org/10.1016/j.paid.2016.07.026

Chabrol, H., Bouvet, R., \& Goutaudier, N. (2017). The Dark Tetrad and antisocial

behavior in a community sample of college students. Journal of Forensic

Psychology Research and Practice, 17(5), 295-304.

http://doi.org/10.1080/24732850.2017.1361310

Chabrol, H., Melioli, T., Van Leeuwen, N., Rodgers, R., \& Goutaudier, N. (2015). The

Dark Tetrad: Identifying personality profiles in high-school students.

Personality and Individual Differences, 83, 97-101.

http://doi.org/10.1016/j.paid.2015.03.051

Chabrol, H., van Leeuwen, N., \& Rodgers, R.F. (2011). Exploratory study of the relations between sadistic traits and suicidality in a nonclinical sample of adolescents. Bulletin of the Menninger Clinic, 75(3), 224-235.

http://doi.org/10.1521/bumc.2011.75.3.224

Chabrol, H., Van Leeuwen, N., Rodgers, R., \& Séjourné, N. (2009). Contributions of psychopathic, narcissistic, Machiavellian, and sadistic personality traits to juvenile delinquency. Personality and Individual Differences, 47(7), 734-739. http://doi.org/10.1016/.jpaid.2009.06.020

Cohen, J. (1988). Statistical power analysis for the behavioral sciences (2nd ed.).

Hillsdale, NJ: Lawrence Erlbaum Associates.

Dhingra, K., \& Boduszek, D. (2013) Psychopathy and Criminal Behaviour: A

Psychosocial Research Perspective. Journal of Criminal Psychology, 3(2),

83-107. https://doi.org/10.1108/icp-06-2013-0014

Dhingra, K., Boduszek, D., \& Kola-Palmer, S. (2015). A Latent Class Analysis of Psychopathic Traits in Civil Psychiatric Patients: The Role of Criminal 
Behaviour, Violence, and Gender. The Howard Journal of Criminal Justice, 54(3), 237-249. http://doi.org/10.1111/hojo.12128

Dinić, B.M., \& Jevremov, T. (2021). Trends in research related to the Dark Triad: A bibliometric analysis. Current Psychology, 40, 3206-3215.

https://doi.org/10.1007/s12144-019-00250-9

Dinić, B.M., Bulut Allred, T., Petrović, B., \& Wertag, A. (2020). A test of three sadism measures. Short Sadistic Impulse Scale, Varieties of Sadistic Tendencies, and Assessment of Sadistic Personality. Journal of Individual Differences, 41, 219-227. https://doi.org/10.1027/1614-0001/a000319 Dinić, B.M., Petrović, B., \& Jonason, P. K. (2018). Serbian adaptations of the Dark Triad Dirty Dozen (DTDD) and Short Dark Triad (SD3). Personality and Individual Differences, 134, 321-328.

https://doi.org/10.1016/j.paid.2018.06.018

Dinić, B.M., Sadiković, S., \& Wertag, A. (2020). Factor mixture analysis of the Dark Triad and Dark Tetrad. Could sadism make a difference? Journal of Individual Differences., 42(2), 74-83. https://doi.org/10.1027/1614$\underline{0001 / a 000331}$

Dinić, B.M., Wertag, A., Sokolovska, V., \& Tomašević, A. (2019). Centrality and redundancy of the Dark Tetrad traits. Personality and Individual Differences, 155. Online fist. https://doi.org/10.1016/j.paid.2019.109621

Edgemon, T. G., \& Clay-Warner, J. (2019). Inmate mental health and the pains of imprisonment. Society and Mental Health, 9(1), 33-50. https://doi.org/10.1177/2156869318785424

Egan, V., Chan, S., \& Shorter, G.W. (2014). The Dark Triad, happiness and subjective well-being. Personality and Individual Differences, 67, 17-22. http://doi.org/10.1016/j.paid.2014.01.004

Eriksson, T. G., Masche-No, J. G., \& Dåderman, A. M. (2017). Personality traits of prisoners as compared to general populations: Signs of adjustment to 
the situation? Personality and Individual Differences, 107, 237-245.

https://doi.org/10.1016/.j.paid.2016.11.030

Evans, C., Mellor-Clark, J., Margison, F., Barkham, M., Audin, K., Connell, J., \&

McGrath, G. (2000). CORE: Clinical Outcomes in Routine Evaluation.

Journal of Mental Health, 9(3), 247-255.

https://doi.org/10.1080/713680250

Fazel, S., Hayes, A. J., Bartellas, K., Clerici, M., \& Trestman, R. (2016). Mental health of prisoners: Prevalence, adverse outcomes, and interventions. The Lancet Psychiatry, 3(9), 871-881. http://doi.org/10.1016/S2215-

$\underline{0366(16) 30142-0}$

Furnham, A., Richards, S.C., \& Paulhus, D.L. (2013). The Dark Triad of personality: A 10 year review. Social and Personality Psychology Compass, 7(3), 199216. http://doi.org/10.1111/spc3.12018

George, D., \& Mallery, M. (2010). SPSS for Windows Step by Step: A Simple Guide and Reference, 17.0 update (10a Ed.). Boston: Pearson.

Gómez-Leal, R., Megías-Robles, A., Gutiérrez-Cobo, M.J., Cabello, R., FernándezAbascal, E.G., \& Fernández-Berrocal, P. (2019). Relationships between the Dark Triad and depressive symptoms. PeerJ, 7:e8120.

http://doi.org/10.7717/peeri.8120

Hair, J.F.Jr., Anderson, R.E., Tatham, R.L., \& Black, W.C. (1995). Multivariate Data Analysis (3rd ed). New York: Macmillan.

Hare. R.D., \& Neumann, C.S. (2008). Psychopathy as a clinical empirical construct. Annual Review of Clinical Psychology, 4, 217-146.

http://doi.org/10.1146/annurev.clinpsy.3.022806.091452

Hepper, E.G., Hart, C.M., Meek, R., Cisek, S., \& Sedikides, C. (2014). Narcissism and empathy in young offenders and non-offenders. European Journal of Personality, 28(2), 201-210. http://doi.org/10.1002/per.1939 IBM Corp. (2019). IBM SPSS Statistics for Windows, Version 26.0. Armonk, NY: IBM Corp. 
Jonason, P.K., Baughman, H M., Carter, G.L., \& Parker, P. (2015). Dorian Gray without his portrait: Psychological, social, and physical health costs associated with the Dark Triad. Personality and Individual Differences, 78, 5-13. https://doi.org/10.1016/i.paid.2015.01.008

Jones, D.N., \& Paulhus, D.L. (2009). Machiavellianism. In M.R. Leary \& R.H. Hoyle (Eds.), Individual differences in social behavior (pp. 93-108). New York: Gulford.

Jones, D.N., \& Paulhus, D.L. (2014). Introducing the Short Dark Triad (SD3). Assessment, 27(1), 28-41. https://doi.org/10.1177/1073191113514105 Joshanloo, M. (2021). Conceptions of Happiness Mediate the Relationship Between the Dark Triad and Well-Being. Frontiers in Psychology, 12:643351. http://doi.org/10.3389/fpsyg.2021.643351

Kavish, N., Jones, M.A., Rock, R.C., Johnson, A.K., \& Anderson, J.L. (2018). On the overlap between psychopathic traits and Machiavellianism in a forensic population. Journal of Psychopathology and Behavioral Assessment, 41(2), 198-207. http://doi.org/10.1007/s10862-018-9708-0

Kingston, D.A., Seto, M.C., Firestone, P., \& Bradford, J.M. (2010). Comparing indicators of sexual sadism as predictors of recidivism among adult male sexual offenders. Journal of Consulting and Clinical Psychology, 78(4), 574-584. http://doi.org/10.1037/a0019734

Klingzell, I., Fanti, K.A., Colins, O.F., Frogner, L., Andershed, A.-K., \& Andershed, H. (2015). Early Childhood Trajectories of Conduct Problems and CallousUnemotional Traits: The Role of Fearlessness and Psychopathic Personality Dimensions. Child Psychiatry \& Human Development, 47(2), 236-247. http://doi.org/10.1007/s10578-015-0560-0

Kowalski, C.M., Rogoza, R., Vernon, P.A., \& Schermer, J.A. (2018). The Dark Triad and the self-presentation variables of socially desirable responding and self-monitoring. Personality and Individual Differences, 120, 234-237. http://doi.org/10.1016/.jpaid.2017.09.007 
Liu, X., Zhang, F., \& Zhao, G., Chen, Y., Yang, B., \& Zhang, Z. (2017). The Dark Triad, creative and impulsive nonconformity in fraud and violent offenders. Chine Journal of Health Psychology, 8, 1183-1186.

Lyne, K., Barrett, P., Evans, C., \& Barkham, M. (2006). Dimensions of variation on the CORE-OM. British Journal of Clinical Psychology, 45(2), 185-203. https://doi.org/10.1348/014466505X39106

Lyons, M., Evans, K., \& Helle, S. (2019). Do "dark" personality features buffer against adversity? The Associations between cumulative life stress, the Dark Triad, and mental distress. SA GE Open, $9(1)$. Online first. https://doi.org/10.1177/2158244018822383

McCuish, E. C., Corrado, R.R., Hart, S.D., \& DeLisi, M. (2015). The role of symptoms of psychopathy in persistent violence over the criminal career into full adulthood. Journal of Criminal Justice, 43(4), 345-356.

http://doi.org/10.1016/i.jcrimjus.2015.04.008

Muris, P., Merckelbach, H., Otgaar, H., \& Meijer, E. (2017). The malevolent side of human nature. Perspectives on Psychological Science, 12(2), 183-204. http://doi.org/10.1177/1745691616666070

O'Meara, A., Davies, J., \& Hammond, S. (2011). The psychometric properties and utility of the Short Sadistic Impulse Scale (SSIS). Psychological Assessment, 23(2), 523-531. http://doi.org/10.1037/a0022400

Paulhus, D.L. (2014). Toward a Taxonomy of Dark Personalities. Current Directions in Psychological Science, 23(6), 421-426.

\section{https://doi.org/10.1177/0963721414547737}

Paulhus, D.L., \& Williams, K.M. (2002). The Dark Triad of personality: Narcissism, Machiavellianism, and psychopathy. Journal of Research in Personality, 36(6), 556-563. http://doi.org/10.1016/s0092-6566(02)00505-6

Pettersen, C., Nunes, K. L., Kostiuk, N., Jung, S., \& Atlas, M. (2019). Explicit and Implicit Self-Esteem, Narcissism, and Recidivism Risk in a Sample of Men Who Have Sexually Offended Against Children. Archives of Sexual Behavior, 49(4), 1319-1332. http://doi.org/10.1007/s10508-019-01598-6 
Pfattheicher, S., Keller, J., \& Kneževic, G. (2019). Destroying things for pleasure: On the relation of sadism and vandalism. Personality and Individual Differences, 140, 52-56. http://doi.org/10.1016/j.paid.2018.03.049

Pfattheicher, S., Lazarevic, LJ., Asbjørn Nielsen, Y., Westgate, E., Krstić, K., \& Schindler, S. (2021). I enjoy hurting my classmates: On the relation of boredom and sadism in schools. PsyArXiv. https://doi.org/10.31234/osf.io/37ru9

Porter, L. C., \& DeMarco, L. M. (2019). Beyond the dichotomy: Incarceration dosage and mental health. Criminology, 571), 136-156.

https://doi.org/10.1111/1745-9125.12199

Rauthmann, J.F., \& Kolar, G.P. (2012). How "dark" are the Dark Triad traits?

Examining the perceived darkness of narcissism, Machiavellianism, and psychopathy. Personality and Individual Differences, 53(7), 884-889. http://doi.org/10.1016/j.paid.2012.06.020

Rogier, G., Marzo, A., \& Velotti, P. (2019). Aggression Among Offenders: The Complex Interplay by Grandiose Narcissism, Spitefulness, and Impulsivity. Criminal Justice and Behavior, 46(10), 1475-1492. http://doi.org/10.1177/0093854819862013

Saladino, V., Lin, H., Zamparelli, E., \& Verrastro, V. (2021). Neuroscience, Empathy, and Violent Crime in an Incarcerated Population: A Narrative Review. Frontiers in Psychology, 12:694212. http://doi.org/10.3389/fpsyg.2021.694212

Shaffer, C., McCuish, E., Corrado, R. R., Behnken, M. P., \& DeLisi, M. (2015). Psychopathy and violent misconduct in a sample of violent young offenders. Journal of Criminal Justice, 43(4), 321-326. http://doi.org/10.1016/j.jcrimjus.2015.05.008

Službeni glasnik (2005). Krivični zakonik Republike Srbije br. 85/2005, 88/2005 ispr., 107/2005 - ispr., 72/2009, 111/2009, 121/2012, 104/2013, 108/2014, 
94/2016 i 35/2019 Retrived (September 15 ${ }^{\text {th }}$ ) from:

http://www.slglasnik.com

Thiry, B. (2012). An assessment of personality disorders with the Five-Factor

Model among Belgian inmates. International Journal of Law and

Psychiatry, 35(4), 327-333. http://doi.org/10.1016/j.ijlp.2012.04.010

Thomson, N.D., Towl, G.J., \& Centifanti, L.C.M. (2016). The habitual female offender

inside: How psychopathic traits predict chronic prison violence. Law and Human Behavior, 4O(3), 257-269. https://doi.org/10.1037//hb0000178

Trninić, V., Barančić, M., \& Nazor, M. (2008). The Five-Factormodel of personality and aggressiveness in prisoners and athletes. Kinesiology, 40, 170-181.

Van Groningen, A.J., Grawitch, M.J., Lavigne, K.N., \& Palmer, S.N. (2021). Every cloud has a silver lining: Narcissism's buffering impact on the relationship between the Dark Triad and well-being. Personality and Individual Differences, 171, 110549.

https://doi.org/10.1016/.jpaid.2020.110549

Wiench, V. (2019). Do prisoners have a dark personality? An investigation on the Dark Traits in inmates. [Master's thesis, University of Mannheim]. Research Gate.

https://www.researchgate.net/publication/336496193_Do_prisoners_ha ve_a_dark_personality_An_investigation_on_the_Dark_Traits_in_inma $\underline{\text { tes }}$

Womick, J., Foltz, R. M., \& King, L. A. (2019). "Releasing the beast within”? Authenticity, well-being, and the Dark Tetrad. Personality and Individual Differences, 137, 115-125. http://doi.org/10.1016/j.paid.2018.08.022

Yi, Y., Turney, K., \& Wildeman, C. (2017). Mental health among jail and prison inmates. American Journal of Men's Health, 11(4), 900-909.

https://doi.org/10.1177/1557988316681339 


\section{Supplement}

\section{Table A}

\section{Detailed results from all moderation analyses}

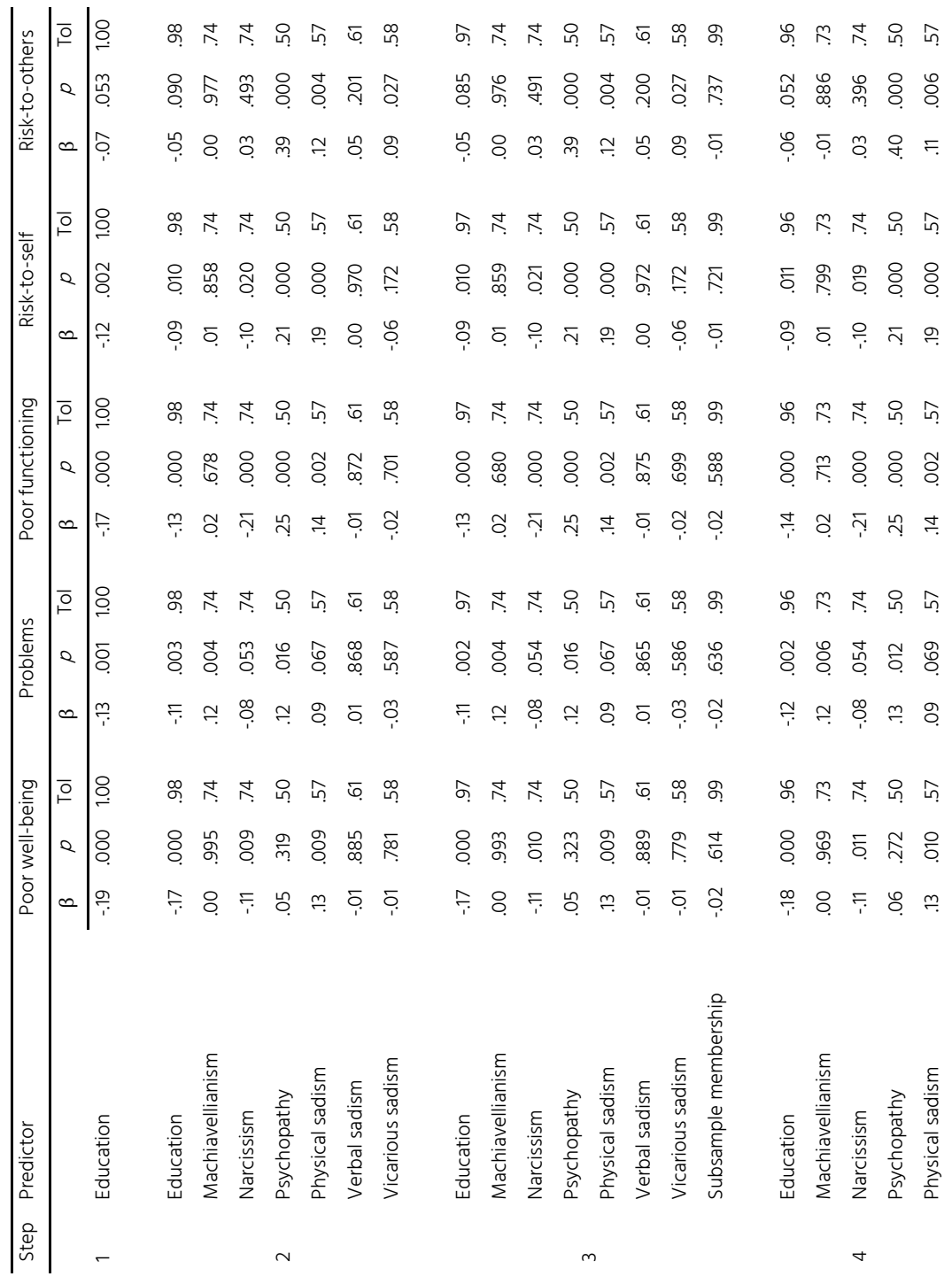

Note: Tol - tolerance. 
